\title{
Undergraduate Engineering Students' Understanding of Heat, Temperature, and Energy: An Examination by Gender and Major*
}

\author{
Katharyn E. K. Nottis, Michael J. Prince, Margot A. Vigeant \\ Bucknell University, Lewisburg, P.A., USA
}

\begin{abstract}
Previous research has found that engineering students have difficulty distinguishing among heat, energy, and temperature concepts. Factors affecting the rate and amount of heat transferred, distinctions between temperature and energy, differences between temperature and how hot/cold something feels, and the effects of surface properties on heat transfer by radiation have been recurrently problematic. Since graduates need to understand these concepts to work with a variety of process operations, there is a need for them to understand these concepts after instruction. This exploratory study sought to determine whether undergraduate engineering students' knowledge of four crucial concept areas in heat transfer significantly changed after instruction and whether this differed by gender and engineering major. Results showed that while participants significantly improved from pre-test to post-test, there was a moderate effect and the mean score on the post-test was below what most have considered concept mastery. The mean post-test score for males was significantly higher than that of females, and females did not significantly improve from pre-test to post-test. A significant interaction between gender and major was also found. Implications of the findings and suggestions for future research are provided.
\end{abstract}

Keywords: engineering education, misconceptions about temperature, gender differences, conceptual learning and assessment, higher education

\section{Introduction}

Heat, temperature, and energy concepts appear throughout pre-college and university science curricula (Jasien \& Oberem, 2002). Despite their recurrence, it has been found that students have difficulty understanding and distinguishing among them (e.g., Carlton, 2000; Streveler, Litzinger, Miller, \& Steif, 2008; Thomaz, Malaquias, Valente, \& Antunes, 1995). One key reason could be the pre-conceptions held by learners. Students' prior knowledge has a key influence on what and how much they learn (Shuell, 2003), and while it provides learners with an explanatory structure to communicate and organize the world (Smith, 1991), it can contain incorrect conceptual understandings, which persist even after instruction (Smith, diSessa, \& Roschelle, 1993). For example, Steveler et al. (2008) determined that students at different grade levels believed that temperature was a good measure of energy in a system.

\footnotetext{
* Acknowledgements: This work was generously supported by the National Science Foundation (NSF) through DUE-0717536.

Katharyn E. K. Nottis, Ph.D., professor, Department of Educational Psychology, Bucknell University.

Michael J. Prince, Ph.D., professor, Department of Chemical Engineering, Bucknell University.

Margot A. Vigeant, Ph.D., professor, Department of Chemical Engineering, Bucknell University.
} 
Prior knowledge with scientifically incorrect understandings has been labeled alternative frameworks (Eylon \& Linn, 1988) or misconceptions (Byrnes, 2008), although the most commonly used descriptor has been misconception (Peşman \& Eryilmaz, 2010). Misconceptions can come from formal/informal schooling and experiential learning (Smith, diSessa, \& Roschelle, 1993) and can be difficult to alter (Self et al., 2008).

\section{Misconceptions About Heat, Temperature, and Energy}

Students in college level science (Jasien \& Oberem, 2002) and engineering programs (Miller et al., 2006; Prince \& Vigeant, 2006; Self et al., 2008) had been found to hold multiple misconceptions about heat, temperature, and energy. For example, Prince and Vigeant (2006) found that many engineering undergraduates viewed heat and temperature as equivalent entities while Self et al. (2008) determined that almost $30 \%$ of chemical and mechanical engineering seniors could not understand “... Logically distinguish between temperature and energy in simple engineering systems and processes” (p. S2G-1). Related content areas which have been recurrently problematic for engineering students have included factors that affect the rate and amount of heat transferred, distinctions between temperature and energy, differences between temperature and perceptions of hot/cold, and the effects of surface properties on heat transfer by radiation (Miller et al., 2006; Prince \& Vigeant, 2006). Each of these areas is important in engineering practice.

Misconceptions about the factors affecting the rate and amount of heat transferred have been identified previously in the research (e.g., Nottis, Prince, \& Vigeant, 2010a; Prince, Vigeant, \& Nottis, 2009a). It has been found that engineering students frequently confound factors that influence the rate of energy transfer with factors that determine the total amount of energy transferred in a given situation.

Streveler et al. (2008) indicated that distinctions between temperature and energy was also an area where students commonly had misconceptions, most notably that temperature was a measure of the energy contained in an object. This finding was determined in part by a Delphi study (Streveler, Olds, Miller, \& Nelson, 2003) where engineering educators were asked to identify topics that were both important and difficult for students to understand, and in part by previous research with engineering students (e.g., Miller et al., 2006).

Knowledge of hot and cold, first learned experientially (Carlton, 2000), can contain different misconceptions. Thomaz et al. (1995) identified five that were frequently seen and noted the difficulty learners had distinguishing been heat and temperature. A common misconception seen with both children and adults is that temperature is a measure of how hot/cold something feels (e.g., Carlton, 2000; Lewis \& Linn, 2003; Prince \& Vigeant, 2006).

Finally, thermal radiation has also been found to be an area where students have recurrent misconceptions (e.g., Jacobi, Martin, Mitchell, \& Newell, 2003; Omar, Zulkifli, \& Hassan, 2009; Streveler et al., 2003.). Undergraduate engineering students often have misconceptions about the effect of surface properties on the rate of heat transfer via thermal radiation (Nottis, Prince, \& Vigeant, 2010a; Prince, Vigeant, \& Nottis, 2009a). For example, learners frequently do not understand that black painted surfaces not only absorb but also emit thermal radiation at a faster rate than polished metal surfaces.

With the recurrence and persistence of misconceptions, it is important for instructors to assess students' prior knowledge as well as their understanding after instruction in order to determine whether conceptual knowledge has altered (Petcovic \& Ruhf, 2008). 


\section{Assessing Misconceptions With Concept Inventories}

One way to evaluate students' understanding of science and engineering concepts is to use concept inventories or multiple-choice assessments modeled on the force concept inventory (FCI) (Hestenes, Wells, \& Swackhamer, 1992). Previous research (e.g., Wuttiprom et al., 2009) had indicated that "conceptual surveys" (p. 632) had a number of advantages including easy administration, objective scoring, and being able to be quantitatively analyzed.

Starting in the 1990s, the foundation coalition (FC) led the movement to use concept inventories in engineering (Evans et al., 2003) and multiple ones are currently in use. One such concept inventory is the heat and energy concept inventory (HECI) (Prince, Vigeant, \& Nottis, 2009b), designed to assess understanding in four areas: factors that affect the rate and amount of heat transferred, differences between temperature and energy, distinctions between temperature and perceptions of hot/cold, and the effects of surface properties on heat transfer by radiation.

Concept inventories have been utilized in multiple ways. First, they have been used as pre-tests to determine students' prior knowledge. Differences in pre-test scores among students in the same physics class have been found (Kost, Pollack, \& Finkelstein, 2007; Noack, Antimirova, \& Milner-Bolotin, 2009). Even more, disturbing is that some research has found that discrepancies between those who scored higher and those who scored lower on pre-tests were maintained throughout an entire course (Noack, Antimirova, \& Milner-Bolotin, 2009).

Shallcross (2010) had suggested that by comparing pre-test with post-test results, concept inventories can be used to quantify students' improvement in understanding and the "... level to which the misconceptions have been corrected" (p. e. 2). Use of pre-post testing with concept inventories has revealed that some misconceptions do not alter after instruction, especially if traditional instructional methods are employed (Suping, 2003). Although Self et al. (2008) noted that it was difficult to alter misconceptions with a lecture approach, engineering faculty had informally reported that instruction related to heat transfer concepts typically involved what would be considered a lecture model (Prince, 2009). Preconceptions are generally not assessed, because it is assumed that good grades in pre-requisite courses mean that students understand concepts covered in those courses. However, this is not necessarily the case (e.g., Byrnes, 2008).

Concept inventories have also shown that conceptual understanding in both the sciences and engineering can vary according to different characteristics of the participants, such as gender (Nottis, Prince, \& Vigeant, 2010b) and major (Nottis, Prince, \& Vigeant, 2009; 2010b). There is a need to examine these variables when looking at students' conceptual understanding and the persistence of misconceptions.

\section{Gender and Cognitive Outcomes}

Belenky, Clinchy, Goldberger, and Tarule (1986) examined the impact of gender on the development of cognitive reasoning. Other researchers have compared males' and females' performance in physics (e.g., Docktor \& Heller, 2008; Kost, Pollock, \& Finkelstein, 2007; Noack, Antimirova, \& Milner-Bolotin). Still others have considered the impact of multiple variables on gender differences in understanding science content (e.g., Chambers \& Andre, 1997; Noack, Antimirova, \& Milner-Bolotin, 2009).

A pattern of females having lower pre-test scores on conceptual assessments than males has been revealed in physics education research (e.g., Docktor \& Heller, 2008; Kost, Pollock, \& Finkelstein, 2007; Noack, 
Antimirova, \& Milner-Bolotin, 2009). For example, Kost, Pollock, and Finkelstein (2007) found that a greater percentage of females were in the low pre-test score group than males when given the Force and Motion Concept Evaluation (FMCE) (Thornton \& Sokoloff, 1998). The researchers also determined that pre-test scores accounted for $34 \%$ of the variance in post-test scores. Kost, Pollock, and Finkelstein (2007) concluded that the gender gaps revealed the result of differences in preparation.

Noack, Antimirova, and Milner-Bolotin (2009) also found that females had lower pre-test scores on average than males when assessed with the FCI (Hestenes, Wells, \& Swackhamer, 1992) in an introductory undergraduate physics course. Females scored about $14 \%$ lower than males. This discrepancy was maintained throughout the course, despite the use of "interactive teaching methods" (p. 1273), something the researchers noted was recommended for reducing gender differences in the classroom.

Chambers and Andre (1997) studied the effect of prior experience, interest, and knowledge on gender differences in understanding science content. The researchers discovered that males out-performed females when assessed on their understanding of electrical current. However, when prior knowledge, experience, and interest were controlled, there was no significant main effect for gender. Other researchers have also examined the effect of subject characteristic variables to determine their impact on student outcomes in science and math courses. In another study, Cubbon, Hoffman, and Nottis (2008) determined that there was a moderate, significant, and negative correlation between believing a science course was interesting and feelings of anxiety and nervousness with high school females. When interest in the course was controlled, there was a significant and positive association between females actively participating in the current science course and their motivation to succeed, presumably leading to better achievement.

Noack, Antimirova, and Milner-Bolotin (2009) examined the effect of gender, minority status, language, country of origin, parents' university background, and the completion of a high-level physics course on students' performance on the FCI (Hestenes, Wells, \& Swackhamer, 1992). The researchers found that those who had previously taken a high-level physics course at the end of high school did better on the pre-test than those that did not, illustrating the importance of prior knowledge. Further, males were more likely to have taken such a course ( 9 out of 10) than females ( 6 out of 10) pointing to how varied educational backgrounds may affect gendered findings.

\section{The Effect of Background and Major on Gendered Findings}

There have been indicators in previous research that educational background or major may confound findings related to gender (e.g., Chambers \& Andre, 1997; Noack, Antimirova, \& Milner-Bolotin, 2009). For example, Noack, Antimirova, and Milner-Bolotin (2009) found that students who had a high-level physics course in high school had higher pre-test scores on the FCI (Hestenes, Wells, \& Swackhamer, 1992) in a college physics course than those that had not taken such a course. Yet, the introductory course from which participants were drawn for this study included students enrolled in chemistry, biology, medical, physics, and general science degrees. Students pursuing some of these majors might not have been interested in an advanced physics course in high school. In addition, females might not have taken such a course in high school given that they would have been less likely to major in physics.

Rosser (2003) indicated that while the number of women selecting science and technology majors had increased since the 1960s, the number choosing careers in computer science, physical science, and engineering remains lower than with other majors in science. De Cohen (2009) had noted that females got approximately $20 \%$ of university degrees in engineering despite getting more than half of all bachelor's degrees. This has led to 
speculation about reasons for the pattern. One related issue that has been raised is the educational environment for women who pursue these careers.

\section{Classroom and Campus Climate}

Issues related to classroom and campus climate are particularly important in engineering since the rate of females pursuing technical and engineering postsecondary studies continues to lag behind that of males (Cavanagh, 2007; de Cohen, 2009; Rosser, 2003) and remains an ongoing concern.

Science, technology, engineering, and mathematics' (STEM) disciplines and careers have been perceived as masculine domains (Bernstein \& Russo, 2008; MacPhee, Farro, \& Canetto, 2013). Gendered models in these fields, including engineering, may dissuade females from establishing a science identity (Williams \& George-Jackson, 2014), which in turn could impact their academic achievement and persistence. Previous research (e.g., Wyer, 2003) discovered that persistence in science and engineering was linked to positive images of scientists and engineers, encouraging attitudes about gender equality in science and engineering, and classroom experiences in science and engineering courses where students perceived there was gender and ethnic fairness. When compared with males, Wyer (2003) found that females had a lower commitment to persistence, more positive views of gender equality, and an increased awareness of classroom climate. However, participants in this study were from two different majors-biology and engineering. The majority of the biology majors were females while the majority of the engineering majors were males.

There are other factors in the classroom environment that have been uncovered which affect the original interpretation of new content information. One of these has been labeled as "social cues," "anticipated reactions of others... To what I say/do," "their potential for being helpful," and "how well I fit in and/or feel comfortable with the assembled group..." (Shuell, 2003, p. 14). Classroom climate can be particularly important when learning new content.

Campus and classroom climate has also been examined to determine whether these variables impact cognitive outcomes in females (e.g., Pascarella et al., 1997; Whitt et al., 1999). A perceived "chilly climate" was found to have a statistically significant negative relationship with four of five areas of self-reported cognitive gains in female sophomores and juniors at four-year colleges, including understanding of science (Whitt et al., 1999). This perceived "chilly climate" (Pascarella et al., 1997; Whitt et al., 1999) could also be related to the differential patterns of interaction between students and university faculty in different majors. For example, previous research has indicated that students in humanities and social science fields reported more interaction with faculty than students in professional and science or math related fields (Kuh \& $\mathrm{Hu}, 2001$ ). This could be a key issue for females because of their awareness of classroom climate (Wyer, 2003) and professor-student's interaction. As a result, females' initial understanding of content presented in the classroom may be impacted (Shuell, 2003).

Awareness of environmental issues can provide an interpretive lens from which understand discrepant findings between males and females.

\section{The Purpose of the Study}

Given engineering students' difficulties learning heat, temperature, and energy concepts (Miller et al., 2006; Prince \& Vigeant, 2006; Self et al., 2008), there is a need to explore whether conceptual knowledge alters after instruction. In addition, in light of previous research in physics, gender remains an important variable to examine when looking at students' performance. Do male and female engineering majors have differing 
pre-test scores on concept inventories? If so, is there any discrepancy between males and females maintain after instruction? Given that gendered patterns found in physics may have been confounded by other background variables, there also remains a need to examine major.

Therefore, the purpose of this exploratory study was threefold. The first was to determine whether undergraduate engineering students' prior knowledge of four crucial concept areas in heat transfer significantly changed after instruction: factors that affect "rate $v s$. amount of heat transferred," "temperature $v s$. perceptions of hot/cold," "energy vs. temperature," and "thermal radiation." The HECI (Prince, Vigeant, \& Nottis, 2009b) was used to assess these areas with questions targeting previously documented misconceptions in each topic. Table 1 indicates the heat transfer areas and the misconceptions commonly found in each.

Table 1

Heat Transfer Misconception Areas Targeted in the Study

\begin{tabular}{|l|l|}
\hline Content area & Previously identified misconceptions \\
\hline $\begin{array}{l}\text { 1. Rate } v s . \text { amount of heat } \\
\text { transferred }\end{array}$ & $\begin{array}{l}\text { Many students seem to believe that factors which increase the rate of heat transfer always increase the } \\
\text { amount of heat transferred as well. These misconceptions carry over to related fields, such as mass } \\
\text { transfer. }\end{array}$ \\
\hline $\begin{array}{l}\text { 2. Temperature } v s . \\
\text { perceptions of hot/cold }\end{array}$ & $\begin{array}{l}\text { Many students think that temperature is a measure of how hot or cold things feel. Many students do } \\
\text { not understand that other factors, such as the rate of heat transfer, frequently affect how hot/cold } \\
\text { something feels. }\end{array}$ \\
\hline 3. Energy $v$ s. temperature & $\begin{array}{l}\text { Students commonly believe that temperature is a direct measure of the energy in an object, so } \\
\text { something at a higher temperature always has more energy. }\end{array}$ \\
\hline 4. Thermal radiation & Students are often confused about the effect of surface properties on the rate of radiative heat transfer. \\
\hline
\end{tabular}

The second purpose was to discover whether there were significant gender differences in engineering students' prior knowledge and their learning after instruction as measured by the HECI (Prince, Vigeant, \& Nottis, 2009b). Given previous literature from physics education (e.g., Docktor \& Heller, 2008; Kost, Pollock, \& Finkelstein, 2007; Noack, Antimirova, \& Milner-Bolotin, 2009), it was predicted that female engineering students would show a pattern of lower pre-test scores than male engineering majors. Finally, since previous research had found some gendered findings confounded by major (e.g., Chambers \& Andre, 1997; Noack, Antimirova, \& Milner-Bolotin, 2009), this study sought to determine whether there were significant differences in understanding of heat transfer concepts by engineering major and whether major interacted significantly with gender.

\section{Methodology}

\section{Design}

A one-group, pre- and post- test design was utilized in this study. Descriptive statistics were employed to examine changes in knowledge, as measured by the overall scores of participants on the entire concept inventory, as well as in each conceptual area sub-test. Paired sample $t$-tests were utilized to test the significance of changes in knowledge from pre-test to post-test for the entire test and the sub-tests. The McNemar's Chi-Square Test was used for significance testing on individual concept inventory questions (Huck \& Cormier 1996). In order to compute the McNemar change tests, answers on individual pre- and post- test questions were dichotomized into correct and incorrect.

A one-way analysis of variance (ANOVA) was used to examine differences in performance by gender and a two-way ANOVA was done to investigate differences in performance by gender and major. 
To determine the internal consistency reliability of the instrument, the Kuder-Richardson Formula 20 (KR-20) was computed on the total post-test and for each of the post sub-tests. The KR-20 was used, because it could not be assumed that all of the questions in the HECI (Prince, Vigeant, \& Nottis, 2009b) were of equal difficulty and this approach is recommended when that is the case (Fraenkel, Wallen, \& Hyun, 2012).

\section{Participants}

A convenience sample of 152 undergraduate engineering students from five institutions in diverse locations in the United States, participated in this exploratory study and 145 were assessed in the first couple weeks of class, prior to instruction on the target concepts. The students were then evaluated in the last two weeks of the course with the same instrument $(n=142)$. Not all participants provided demographic information nor completed both the pre- and post- test on concept inventory. This resulted in differing numbers in some of the demographic information and analyses.

In the current sample, females were $27 \%(n=41)$ and males were $73 \%(n=111)$. Sixty-one students were mechanical engineering majors, 57 were chemical engineering majors, 14 were civil engineering majors, and 20 were distributed among "other" engineering majors. At one institution, there was a general engineering major and those participants were grouped into the "other" category. As can be seen in Table 2, the majority of female students were chemical engineering majors.

Table 2

Engineering Major by Gender

\begin{tabular}{lll}
\hline Engineering major & Female $(n=41)$ & Male $(n=111)$ \\
\hline Chemical & 24 & 33 \\
Mechanical & 6 & 55 \\
Civil & 2 & 12 \\
Other & 9 & 11 \\
\hline
\end{tabular}

Participants were primarily juniors with a grade-point average (GPA) of 3.00 or higher (70.2\%). As can be seen in Table 3, the percentage of males and females with a GPA of 3.00 or higher was approximately the same, and about $34 \%$ of females and $32 \%$ of males reported a GPA of 3.50-4.00.

Table 3

Self-Reported GPA by Gender

\begin{tabular}{lll}
\hline GPA range & Percentage of females $(\%)(n=41)$ & Percentage of males $(\%)(n=110)$ \\
\hline $3.50-4.00$ & $34.1(n=14)$ & $31.8(n=35)$ \\
$3.00-3.49$ & $36.6(n=15)$ & $38.2(n=42)$ \\
$2.50-2.99$ & $24.4(n=10)$ & $20.9(n=23)$ \\
$2.00-2.49$ & $4.9(n=2)$ & $8.2(n=9)$ \\
$<2.00$ & 0 & $0.9(n=1)$ \\
\hline
\end{tabular}

Approximately $89 \%$ of the participants were enrolled in a heat transfer course at the time data were collected. About $6 \%$ had not taken a course in heat transfer while the remainder had previously taken a course in this area.

\section{Instruments}

The HECI. The HECI (Prince, Vigeant, \& Nottis, 2009b) was used in the current study. This instrument was patterned after concept inventories used in other disciplines, such as the FCI developed to assess 
Newtonian mechanics in the late 1980s (Hestenes, Wells, \& Swackhamer, 1992). The HECI was designed to document both conceptual change and the presence of previously identified misconceptions about heat and temperature (e.g., Nottis, Prince, \& Vigeant, 2009b; Prince, Vigeant, \& Nottis, 2009a).

The HECI (Prince, Vigeant, \& Nottis, 2009b) had 36 multiple-choice questions targeting four key concept areas: "rate $v s$. amount of heat transferred," "temperature $v s$. perceptions of hot/cold," "energy $v s$. temperature," and "thermal radiation." Groups of questions are collectively considered sub-tests in each of these target areas. The number of questions in each sub-test ranges from a low of eight questions in "rate $v s$. amount" to a high of 11 for thermal radiation. Two questions were determined to fit into two sub-test areas.

Questions in the HECI came from three main sources. Questions were added, with permission, from those being developed and tested in drafts of the thermal and transport science concept inventory (TTCI) (Miller, 2009) and from the HECI (Jacobi et al., 2003). The researchers also formulated additional questions, such as three questions are in common with the TTCI (Miller, 2009) and five are similar but modified versions of TTCI questions. A single question on the HECI (Prince, Vigeant, \& Nottis, 2009b) is a modified version of a question from the heat transfer concept inventory of Jacobi et al. (2003).

Content validity was determined by having all questions critiqued by a panel of faculty who regularly teach an undergraduate heat transfer course. Several cycles of feedback were solicited, and questions were refined in subsequent versions until each of the ten experts agreed that each item in the current version assessed the targeted concept (e.g., "rate $v s$. amount of heat transferred," etc.).

Since misconceptions can come from both everyday experience as well as formal instruction (e.g., Smith, diSessa, \& Roschelle, 1993), some concept inventory questions on the HECI (Prince, Vigeant, \& Nottis, 2009b) incorporate examples from students' prior experiential knowledge, such as cooking. Appendix I provides an example of such a question, developed to assess "energy vs. temperature" when baking a pizza (Question 16). This question is included in "the energy $v$ s. temperature" sub-test.

Other questions on the HECI (Prince, Vigeant, \& Nottis, 2009b) tap into students' current and previous coursework knowledge, as well as their ability to recognize underlying principles and apply them to cases with multiple and different variables. Two examples of this kind of question can be found in Appendix II. Questions 22 and 23 assess students' understanding of mass transfer. They are included in the "rate $v s$. amount of heat transferred" sub-test, because mass transfer follows the same mathematical rules as heat transfer. Chemical species move from high concentrations to low concentrations just like energy flows from high temperature to low temperature.

Demographic Information. Self-report demographic information was collected from each participant. This included gender, GPA categorized into one of five categories (3.50-4.00, 3.00-3.49, 2.50-2.99, 2.00-2.49, and less than 2.00), engineering major, and whether the participant had previously, currently, or not taken a course in heat transfer.

\section{Procedure}

A paper version of the concept inventory was initially administered in the first couple weeks of the course, prior to instruction on the designated concept areas. The same concept inventory was administered after instruction in the last two weeks of the course. Demographic information was collected with both administrations since some students had not taken the pre-test. 


\section{Findings}

\section{Knowledge of Heat Transfer Concepts}

As can be seen in Table 4, students' post-test scores were higher than their pre-test scores. A paired samples $t$-test revealed there was a significant improvement with a small to medium effect size (Cronk, 2010), $t(134)=-3.81, p<0.01, d=0.33$.

Table 4

Means and Standard Deviations on Entire HECI and by Sub-Test

\begin{tabular}{lll}
\hline Assessment & Mean pre-test score & Mean post-test score \\
\hline Total concept inventory ${ }^{* *}$ (36 questions) & $17.22(47.8 \%)(S D=5.79)(n=145)$ & $18.60(51.7 \%)(S D=6.20)(n=142)$ \\
Rate $v s$. amount of heat transferred (eight & $2.89(S D=2.12)$ & $3.20(S D=2.28)$ \\
questions) & $5.50(S D=2.18)$ & $6.09(S D=1.89)$ \\
Temperature $v s$. feeling ${ }^{* *}$ hot/cold (nine & $5.21(S D=2.10)$ & $5.41(S D=2.09)$ \\
questions) & $4.68(S D=1.99)$ & $5.42(S D=2.55)$ \\
Energy $v s$. temperature (10 questions) $_{\text {Radiation }^{* *} \text { (11 questions) }}$ &
\end{tabular}

Notes. ${ }^{*}$ Difference significant at 0.05 level, as determined by paired samples $t$-test;

${ }^{* *}$ Difference significant at 0.01 level, as determined by paired samples $t$-test.

Participants also significantly improved with small to medium effect sizes on two of the four sub-tests: "temperature vs. perceptions of hot/cold," $t(138)=-3.88, p<0.01, d=0.33$ and "thermal radiation," $t(108)=$ -3.24, $p<0.01, d=0.31$. There was no significant improvement in students' scores from pre-test to post-test on the "rate $v s$. amount of heat transferred" or the "energy $v s$. temperature" sub-tests.

With Question 16 from the "energy vs. temperature" sub-test (see Appendix I), a smaller percentage of students selected the key answer after instruction, although the McNemar Chi-Square Test showed that this change was not statistically significant. On the pre-test, $66.2 \%$ of the participants selected the correct response while on the post-test, $62 \%$ chose the right answer.

On Questions 22 and 23 from the "rate $v s$. amount of heat transferred" sub-test (see Appendix II), one question showed little change from pre-test to post-test, while the other showed a decrease in the percentage of students selecting the correct answer on the post-test. On Question 22, 54.9\% chose the key answer on the pre-test while $58.9 \%$ got the question correct on the post-test, although this change was not significant. Prior to instruction, when participants did not select the correct response, the most frequently selected distracter was "b. The one sponge in the $2 \%$ solution will absorb more dye." After instruction, the most frequently selected incorrect distracter was "a. The two sponges in the $1 \%$ solution will absorb more dye."

With Question 23, the percentage of students correctly answering this question decreased from pre-test to post-test, $41.4 \%$ to $32.6 \%$ respectively, although the McNemar Chi-Square Test revealed the decrease was not statistically significant. On the pre-test, an almost equivalent number of participants selected each distracter, including the correct answer. After instruction, the response picked most frequently and more than the correct answer was "a. Two sponges in the $1 \%$ solution will absorb dye at a faster rate."

\section{Knowledge of Heat Transfer Concepts by Gender}

As can be seen in Table 5, mean scores for females on all pre- and post- tests were lower than that of males.

Although males had higher mean scores than females on the total pre-test, a one-way ANOVA showed that this difference was not statistically significant. However, after instruction, males scored significantly 
higher with a medium effect size (Cohen, 1988; Miles \& Shevlin, 2001) than females on the total post-test, $F(1,140)=10.40, p<0.01$ partial $\eta^{2}=0.07$.

Table 5

Means and Standard Deviations by Gender on Entire HECI (Prince, Vigeant, \& Nottis, 2009b) and by Sub-Test

\begin{tabular}{|c|c|c|}
\hline Test & Female & Male \\
\hline Pre-test total & $15.66(S D=4.80)(n=38)$ & $17.78(S D=6.02)(n=107)$ \\
\hline Post-test total ${ }^{*}$ & $15.89(S D=5.37)(n=38)$ & $19.57(S D=6.22)(n=104)$ \\
\hline Rate $v s$. amount of heat transferred pre-test & $2.68(S D=2.06)$ & $2.86(S D=2.18)$ \\
\hline Rate $v s$. amount of heat transferred post-test & $2.63(S D=2.33)$ & $3.41(S D=2.24)$ \\
\hline Temperature $v s$. perceptions of hot/cold pre-test & $5.03(S D=2.24)$ & $5.68(S D=2.14)$ \\
\hline Temperature $v s$. perceptions of hot/cold post-test ${ }^{*}$ & $5.47(S D=1.81)$ & $6.32(S D=1.88)$ \\
\hline Energy $v s$. temperature pre-test ${ }^{*}$ & $4.54(S D=1.60)$ & $5.45(S D=2.20)$ \\
\hline Energy $v s$. temperature post-test ${ }^{* *}$ & $4.25(S D=1.96)$ & $5.74(S D=2.07)$ \\
\hline Thermal radiation pre-test ${ }^{* *}$ & $3.94(S D=1.85)$ & $5.04(S D=1.96)$ \\
\hline Thermal radiation post-test ${ }^{* *}$ & $4.16(S D=2.09)$ & $5.99(S D=2.52)$ \\
\hline
\end{tabular}

Notes. ${ }^{*}$ Difference significant at 0.05 level;

${ }^{* *}$ Difference significant at 0.01 level.

There was a significant difference between males and females on two of the pre sub-tests: "energy vs. temperature," $F(1,141)=5.35, p<0.05$ and "thermal radiation," $F(1,126)=8.19, p<0.01$. After instruction, there were also significant differences with small to medium effect sizes between males and females on three of the post sub-tests: "temperature $v s$. perceptions of hot/cold," $F(1,140)=5.71, p<0.05$, partial $\eta^{2}=0.04$; "energy vs. temperature," $F(1,134)=15.21, p<0.01$, partial $\eta^{2}=0.10$; and "thermal radiation," $F(1,116)=$ $14.58, p<0.01$, partial $\eta^{2}=0.11$. In all cases, males scored significantly higher than females.

Inspection of the pre-post performance of each gender separately, using a paired samples $t$-test, revealed that females did not significantly improve from pre-test to post-test on the entire concept inventory nor any sub-tests, whereas males did show significant improvement with a small effect size, from pre-test to post-test on the total concept inventory, $t(99)=-3.88, p<0.01, d=0.39$ and three of the four sub-tests: "rate $v s$. amount of heat transferred," $t(101)=-2.17, p<0.05$; "temperature $v s$. perceptions of hot/cold," $t(101)=-3.71, p<0.01$; and "thermal radiation," $t(74)=-3.32, p<0.01$. Neither males nor females significantly improved from pre-test to post-test on the "energy $v s$. temperature" sub-test.

Table 6

Percentage Correct on Question \#16

\begin{tabular}{lll}
\hline Respondents & Pre-test (\%) & Post-test (\%) \\
\hline Total group & 66.2 & 62.0 \\
Females only & $73.7(n=38)$ & $52.6(n=38)$ \\
Males only & $63.6(n=106)$ & $65.4(n=104)$ \\
\hline
\end{tabular}

An examination of the percentage of students correctly answering targeted Questions (16, 22, and 23) showed variations by gender. As can be seen in Table 6, the percentage of females correctly answering Question 16 (pizza baking), decreased from pre-test to post-test while the percentage of males getting this question correct slightly increased. However, the McNemar Chi-Square Test showed that neither change was significant. 
An examination of the post-test answers for Question 16 that were selected by females indicated that an increased number chose each of the three other distracters while a decreased number picked the correct response. On the pre- and post- tests, both males and females who did not select the correct response, chose option "b" more frequently than the other distracters: "The pizza cooked in the $700{ }^{\circ} \mathrm{F}$ oven for five minutes had more energy transferred to it."

In terms of Question 22, as can be seen in Table 7, the percentage correctly answering the question decreased for females and increased for males from pre-test to post-test, although the McNemar Chi-Square Test showed that the changes were not significant. More females and males selected distracter "a" after instruction: "The two sponges in the $1 \%$ solution will absorb more dye."

Table 7

Percentage Correct on Question 22

\begin{tabular}{lll}
\hline Respondents & Pre-test $(\%)$ & Post-test $(\%)$ \\
\hline Total group & 54.9 & 58.9 \\
Females only & $57.9(n=38)$ & $50.0(n=38)$ \\
Males only & $53.8(n=106)$ & $62.1(n=104)$ \\
\hline
\end{tabular}

As shown in Table 8, a smaller percentage of both males and females got Question 23 correct on the post-test when compared with the pre-test, but again, these changes were not significant. In this case, both selected distracter "a" as the correct answer more frequently on the post-test than pre-test indicating that they felt two sponges in the $1 \%$ solution would absorb dye at a faster rate.

Table 8

Percentage Correct on Question 23

\begin{tabular}{lll}
\hline Respondents & Pre-test $(\%)$ & Post-test $(\%)$ \\
\hline Total group & 41.4 & 32.6 \\
Females only & $39.5(n=38)$ & $21.1(n=38)$ \\
Males only & $42.1(n=106)$ & $36.9(n=104)$ \\
\hline
\end{tabular}

\section{Knowledge of Heat Transfer Concepts by Major}

Table 9 shows that mean scores on both the total pre- and post- test were much lower for civil engineering majors than that of the other majors.

One-way ANOVA showed significant differences among majors on both the pre-test, $F(3,141)=5.91, p<$ 0.01 and the post-test, $F(3,138)=6.13, p<0.01$, partial $\eta^{2}=0.12$. Tukey post-hoc follow-up tests revealed that civil engineering majors scored significantly lower than all other majors.

Table 9

Means and Standard Deviations by Major on Entire HECI (Prince, Vigeant, \& Nottis, 2009b)

\begin{tabular}{lll}
\hline Major & Mean pre-test score & Mean post-test score \\
\hline Chemical engineering & $17.83(S D=5.76)(n=54)$ & $19.93(S D=6.51)(n=53)$ \\
Mechanical engineering & $17.83(S D=5.98)(n=58)$ & $18.86(S D=5.46)(n=58)$ \\
Civil engineering & $11.08(S D=4.86)(n=13)$ & $12.15(S D=5.61)(n=13)$ \\
Other & $17.80(S D=3.30)(n=20)$ & $18.39(S D=5.46)(n=18)$ \\
\hline
\end{tabular}

When the four sub-tests were examined with one-way ANOVA, a significant difference was found with the "temperature $v s$. perceptions of feeling hot/cold" sub-test on both the pre-test, $F(3,145)=4.23, p<0.01$ and 
the post-test with the post-test having a medium effect size, $F(3,138)=4.31, p<0.01$, partial $\eta^{2}=0.09$. Tukey follow-up comparisons showed that on the pre-test, chemical engineering and other engineering majors scored significantly higher than civil engineering majors. On the post-test, chemical engineering majors had a significantly higher mean score than the civil engineering majors.

A significant difference was also found on the "energy $v$ s. temperature" post-test with a medium effect size, $F(3,132)=3.89, p<0.05$, partial $\eta^{2}=0.08$. Tukey post-hoc comparisons showed that chemical and mechanical engineering majors scored significantly higher than civil engineering majors.

\section{The Interaction of Gender and Major}

A two-way ANOVA revealed a significant interaction between gender and major for the entire instrument on the post-test, $F(3,142)=2.72, p<0.05$, partial $\eta^{2}=0.06$, although the effect size was moderately small.

As can be seen in Table 10, female chemical engineering majors had lower mean pre- and post- test scores than males. By contrast, female mechanical and civil engineering majors had higher mean pre-test scores than males.

Table 10

Means by Gender and Major on Entire HEC (Prince, Vigeant, \& Nottis, 2009b)

\begin{tabular}{lllll}
\hline \multirow{2}{*}{ Major } & \multicolumn{3}{c}{ Mean pre-test score } & \multicolumn{2}{c}{ Mean post-test score } \\
\cline { 2 - 3 } & Female & Male & Female & Male \\
\hline Chemical engineering & 14.74 & 20.13 & 15.45 & 23.10 \\
Mechanical engineering & 19.60 & 17.66 & 18.00 & 18.96 \\
Civil engineering & 12.00 & 11.00 & 15.00 & 11.92 \\
Other & 16.22 & 19.09 & 15.67 & 21.11 \\
\hline
\end{tabular}

After instruction, female mechanical and "other" engineering majors had lower mean scores than on the pre-test. Scores of males in all majors increased from pre-test to post-test.

\section{Internal Consistency Reliability of the HECI}

Internal consistency reliability of the entire post-test and each post sub-test of the HECI (Prince, Vigeant, \& Nottis, 2009b) was determined using the KR-20. Results shown in Table 11 indicated that the estimate of internal reliability of the entire concept inventory was acceptable for research purposes (Fraenkel, Wallen, \& Hyun, 2012). The estimates of internal reliability of the post sub-tests, as measured by the KR-20 ranged from a low of 0.53 for "energy $v s$. temperature" to a high of 0.77 for radiation.

Table 11

Estimates of Internal Consistency Reliability of Entire HECI Post-Test and Post Sub-Tests

\begin{tabular}{ll}
\hline Assessment & KR-20 \\
\hline Entire concept inventory (post-test) (36 Questions) & 0.82 \\
Rate $v$ s. amount of heat transferred sub-test & 0.75 \\
Temperature $v$ s. perceptions of hot/cold sub-test & 0.58 \\
Energy $v s$. temperature sub-test & 0.53 \\
Thermal radiation sub-test & 0.77 \\
\hline
\end{tabular}

\section{Discussion}

Misconceptions resistant to change through traditional teaching methods are of particular interest to engineering educators, especially when these misconceptions concern important heat, energy, and temperature concepts found in core engineering courses. The current research revealed that while students improved their 
understanding of target concept areas after instruction, even when significant differences were found, the mean post-test scores were below what most instructors would consider mastery and the effect sizes were small to medium. Gender differences showed that while there was a significant difference between the pre-test scores of males and females, that difference was not significant. However, the lack of significant improvement from pre-test to post-test by females and the interaction of gender with engineering major may indicate that traditional pedagogies might not work as well for females as males. This could imply that new and different instructional methodologies are needed.

The lack of significant improvement from the pre-test to post-test on both the "rate $v s$. amount of heat transferred" and the "energy vs. temperature" sub-tests are of particular interest and likely the result of a number of factors.

\section{Sub-Test Differences}

The tenacity of misconceptions in heat transfer has been noted by other researchers (e.g., Self et al., 2008) and the number of courses or semesters of physical science has been found to have a "minimal influence" on students' ability to correctly answer questions about heat transfer and thermal equilibrium (Jasien \& Oberem, 2002 , p. 892). Therefore, the difficulty of the concepts involved could explain participants' lack of significant improvement on these two sub-tests. However, there may be other, equally compelling explanations for each sub-test.

A closer examination of the kinds of questions on the "rate $v s$. amount of heat transferred" sub-test shows that $75 \%$ of them require students to incorporate multiple and related concepts in order to solve a problem. This is the case with Questions 22 and 23. As noted previously, there was little change in selection of the correct response from pre-test to post-test on Question 22 and a decrease in the selection of the correct response after instruction with Question 23. This pattern was seen with both males and females.

It has been noted previously (e.g., Jasien \& Oberem, 2002) that heat and temperature questions that involve the integration of multiple ideas are among the most difficult for students. Since the majority of the questions in the "rate vs. amount of heat transferred" sub-test required that students understand the role of multiple variables, this may explain the lack of significant improvement after instruction. Unraveling variables and distinguishing important from unimportant parts of problems was previously noted as an issue in chemistry (Johnstone, 1993). Johnstone (1993) indicated that students often did not know which part(s) of a chemistry problem or experiment is/are most important, and likened learners to “... Drivers in a strange town who do not know what to attend to and, in trying to process too much... Overload" (p. 704). The lack of significant improvement on the "rate $v s$. amount of heat transferred" questions also seems to indicate that the relationship among concepts may need to be made more explicit in instruction. It is not clear in this case, whether the students realized that the same mathematical constructs describe mass and heat transfer. Future research should incorporate findings from novice/expert research in order to more thoroughly examine instructional strategies used to teach the integration of multiple concepts in heat transfer.

When examining the failure to see a significant improvement in the scores of the "energy $v s$. temperature" sub-test, the first issue to be considered is that the reliability of this sub-test was lower than that of the others. It has been noted that for research purposes, the reliability coefficient should be at least 0.70 (Fraenkel, Wallen, \& Hyun, 2012). The KR-20 estimate of the internal consistency reliability for this sub-test was 0.53 . Future research should examine the ways to raise the internal reliability of this sub-test. 
The lack of significant improvement on the "energy $v s$. temperature" sub-test may also be related to the kinds of questions used to assess understanding in this area. Half of the questions on this sub-test involved two variables. As with the "rate vs. amount of heat transferred" sub-test, the issue could be students' difficulty sorting out the multiple variables and distinguishing important from unimportant parts in the question, something that would be difficult for novices.

An examination of Question 16 (pizza question; part of the "energy $v s$. temperature" sub-test) on both the pre- and post- test showed that students who did not select the correct response most frequently chose the distracter (b) where the highest temperature had more energy transferred. The selection of this distracter, even after instruction, showed that students still believed that temperature is a direct measure of the energy in an object, and something at a higher temperature always has more energy. This misconception and others in this conceptual area may be very difficult to alter and could require new, conceptual change instructional methods.

Of particular interest was the fact that fewer females selected the correct response after instruction for Question 16. Their increased selection of other distracters could be indicative of guessing but that raises the issue of why there would be an increased level of guessing for females after instruction. Another explanation for this finding relates to stereotypical gender roles. Perhaps, as a group, the females had more experience with baking food than the males and their interpretations about baking, temperature, and energy conflicted with classroom instruction, and therefore, their confidence about the correct answer. The addition of verbal explanations might have clarified this.

Given that the two sub-tests with the most multiple variable questions showed no significant increases from pre-test to post-test and the two sub-tests where there were significant increases had a majority of one variable questions, future research should also compare students' performance on one variable versus multiple variable questions on the HECI (Prince, Vigeant, \& Nottis, 2009b). Having students provide explanations for answers given for multiple variable questions could allow for greater understanding. It is important to determine if question type is impacting students' showing their conceptual understanding.

\section{Gender Differences}

Although male and female participants had comparable self-reported grade point averages and there was no significant difference on mean pre-test scores, there was a significant difference after instruction on the entire inventory. Males had significantly higher mean post-test scores than females on the entire concept inventory and on three post sub-tests. Further, female students' mean score did not significantly improve from pre-test to post-test whereas the mean score for males did. Chambers and Andre (1997) revealed a similar pattern when investigating undergraduate students' understanding of electrical circuits. The researchers found that after a text intervention (traditional or conceptual change) with or without adjunct questions, males are out-performed females on the post-test. However, when prior knowledge, experience, and interest were controlled, there was no significant main effect for gender. Chambers and Andre (1997) concluded that the apparent gender differences found might have been due to those other variables.

In this study, the findings indicate a need for further research to uncover the reasons for these gender differences. Future research should control for pre-test scores when examining post-test differences. An examination of related courses taken prior to a heat transfer course might reveal whether there are differences in prior knowledge that could be addressed. 
Wyer's (2003) finding that females had an increased sensitivity to classroom environment pointed to the need to study other variables previously associated with cognitive outcomes including a "chilly" university and classroom climate (e.g., Pascarella et al., 1997; Whitt et al., 1999). The addition of a climate measure, such as the "perceived chilly climate for women scale," developed for the National Study of Student Learning (NSSL) (Pascarella et al., 1997; Whitt et al., 1999) in future studies could provide additional insights.

The indication of increased guessing by females after instruction when answering Question 16 points to the need to add a measure of confidence to the HECI (Prince, Vigeant, \& Nottis, 2009b) to help clarify whether this is a variable impacting performance. One possibility is modifying the current instrument, so that it becomes a three-tiered assessment (Peşman \& Eryilmaz, 2010). Three-tiered instruments typically have multiple-choice questions (first-tier) followed by questions where students select the reason why the answer in the first-tier is correct (second-tier), and finally, a measure of students' confidence in the answers selected in the first two tiers (Peşman \& Eryilmaz, 2010). Responses to the different tiered questions are then collectively scored. Previous research (e.g., Planinic, Boone, Krsnik, \& Beifuss, 2006) has found that students' confidence about their answers to very difficult questions varied with some learners very confident in their erroneous answers. The concept inventory used in this exploratory study has some second-tiered questions, so the addition of a confidence indicator would be possible in future research. This type of assessment could reveal whether there are problems with understanding when certain instructional methodologies are used and/or issues related to confidence after instruction.

However, it should be noted that the size of the female sample was disproportionately smaller than the male group from $27 \%$ to $73 \%$. Future research should attempt to use larger, more equivalent samples in order to see whether the results found in the present study can be replicated. The use of either qualitative or mixed methods research designs may also provide more insight into performance discrepancies between males and females.

\section{Differences Among Engineering Majors}

While the results of the current study showed that civil engineering majors scored significantly lower than those from other majors, this finding should be approached with caution due to the small sample size of civil engineering majors who all came from one institution. The outcomes could be reflective of the students at that particular institution rather than of civil engineering majors in general. Future research should increase the number of students from civil engineering or collapse the results of a major category with a smaller number of participants into the "other" major designation.

With this caution, it is also important to consider that the significant differences found among engineering majors could indicate that students may have different background information depending upon engineering major, and that instructors in those areas may emphasize some aspects of heat transfer more than others. Of particular interest is the significant interaction that was found on the post concept inventory between gender and engineering major. This finding may indicate that there are varying classroom climates or diverse pedagogies found in different engineering majors, some female are friendlier than others. Again, this finding should be interpreted with care due to the small number of females in each of the engineering majors' categories.

Future research should continue to examine major as a variable with gender with a larger sample of female participants, using a variety of research designs. Using an explanatory and mixed methods design where 
classroom observations and student focus groups are used as a follow up to concept inventories could provide additional insights and help to "... refine the quantitative findings" (Fraenkel, Wallen, \& Hyun, 2012, p. 561).

\section{Conclusions}

Accurate understanding of heat, energy, and temperature concepts is important in engineering practice. Graduates designing or working with a variety of process operations (e.g., heaters, coolers, heat exchangers, boilers, refrigerators, air conditioners, etc.) need to understand these concepts thoroughly to do their jobs effectively and safely.

Future research should build from the findings of this exploratory study using a variety of research designs and larger, more representative samples of students. Mixed methods designs will facilitate the understanding of variables that may be impacting students' understanding, as will the addition of other assessments to discern the impact of classroom climate on the performance of females. The adaption of the HECI (Prince, Vigeant, \& Nottis, 2009b) to a three-tiered assessment (Peşman \& Eryilmaz, 2010) could help researchers determine whether there is a lack of knowledge or a real misconception as well as the role that confidence plays in students' performances. When discussing the problems students have understanding physics concepts, Planinic et al. (2006) noted that some could be ascribed to “... The presence of students' firm alternative beliefs, but other difficulties may result from a lack of firm concepts of any kind...” (p. 166). In order to better discern this with engineering students' understanding of heat transfer concepts, more and different kinds of data need to be collected. Acquiring a better understanding of students' knowledge and the personal characteristics impacting their learning would ensure that all engineering students understand these concepts and those misconceptions are reduced.

\section{References}

Belenky, M. F., Clinchy, B. M., Goldberger, N. R., \& Tarule, J. M. (1986). Women's ways of knowing: The development of self, voice, and mind. New York, N.Y.: Basic Books.

Bernstein, B. L., \& Russo, N. F. (2008). Explaining too few women in STEM careers: A psychosocial perspective. In M. A. Paludi (Ed.), The psychology of women at work: Challenges and solutions for our female work force (Vol. 2): Obstacles and the identity juggle (pp. 1-33). Westport, C.T.: Praeger/Greenwood.

Byrnes, J. P. (2008). Cognitive development and learning in instructional contexts (3rd ed.). Boston, M.A.: Pearson.

Carlton, K. (2000). Teaching about heat and temperature. Physics Education, 35(2), 101-105.

Cavanagh, S. (2007). When it comes to math and science, mom and dad count. Education Week, 27(9), 8.

Chambers, S. K., \& Andre, T. (1997). Gender, prior knowledge, interest, and experience in electricity and conceptual change text manipulations in learning about direct current. Journal of Research in Science Teaching, 34(2), 107-123.

Cohen, J. (1988). Statistical power analysis for the behavioral sciences (2nd ed.). Hillsdale, N.J.: Erlbaum.

Cronk, B. C. (2010). How to use PASW ${ }^{\circledR}$ statistics: A step-by-step guide to analysis and interpretation (6th ed.). Glendate, C.A.: Pyrczak.

Cubbon, N., Hoffman, L., \& Nottis, K. (2008, October). Female adolescents in high school science: The role of science self-efficacy and interest. In The Northeastern Educational Research Association Conference. Rocky Hill, C.T..

de Cohen, C. C. (2009, October). Retention is not the problem: Women are not being drawn to engineering in the first place. Retrieved April 10, 2010, from http://www.prism magazine.org/oct09/tt-02.cfm

Docktor, J., \& Heller, K. (2008). Gender differences in both force concept inventory and introductory physics performance. Proceedings of the 2008 Physics Education Research Conference, 1064, 15-18.

Evans, D., Gray, G., Krause, S., Martin, J., Midkiff, C., Notaros, B., ... Wage, K. (2003). Progress on concept inventory assessment tools. In Proceedings of the 33rd ASEE/IEEE Frontiers in Education Conference, T4G1-T4G8.

Eylon, B., \& Linn, M. C. (1988). Learning and instruction: An examination of four research perspectives. Review of Educational Research, 58(3), 251-301. 
Fraenkel, J. R., Wallen, N. E., \& Hyun, H. H. (2012). How to design and evaluate research in education (8th ed.). New York, N.Y.: McGraw-Hill Higher Education.

Hestenes, D., Wells, M., \& Swackhamer, G. (1992). Force concept inventory. The Physics Teacher, 30(3), 141-158.

Huck, S. W., \& Cormier, W. H. (1996). Reading statistics and research (2nd ed.). New York, N.Y.: Harper Collins College Publishers.

Jacobi, A., Martin, J., Mitchell, J., \& Newell, T. (2003). A concept inventory for heat transfer. In Proceedings of the 33rd ASEE/IEEE Frontiers in Education Conference (Paper T3D-12). Boulder, C.O..

Jasien, P. G., \& Oberem, G. E. (2002). Understanding of elementary concepts in heat and temperature among college students and K-12 teachers. Journal of Chemical Education, 79(7), 889-895.

Johnstone, A. H. (1993). The development of chemistry teaching: A changing response to changing demand. Journal of Chemical Education, 70(9), 701-705.

Kost, L. E., Pollock, S. J., \& Finkelstein, N. D. (2007). Investigating the source of the gender gap in introductory physics. In L. Hsu (Ed.), 2007 Physics Education Research Conference Proceedings (pp. 136-139). Melville, N.Y.: American Institute of Physics.

Kuh, G. D., \& Hu, S. (2001). The effects of student-faculty interaction in the 1990s. The Review of Higher Education, 24(3), 309-332.

Lewis, E., L., \& Linn, M., C. (2003). Heat, energy, and temperature concepts of adolescents, adults, and experts: Implications for curricular improvements. Journal of Research in Science Teaching, 40, 155-175.

MacPhee, D., Farro, S., \& Canetto, S. S. (2013). Academic self-efficacy and performance of underrepresented STEM majors: Gender, ethnicity, and social class patterns. Analysis of Social Issues and Public Policy, 13(1), 347-369.

Miles J., \& Shevlin M. (2001). Applying regression and correlation: A guide for students and researchers. London: Sage.

Miller, R. L. (2009). Thermal and transport concept inventory. Retrieved September 20, 2009, from http://thermalinventory.com

Miller, R. L., Streveler, R. A., Olds, B. M., Chi, M. T. H., Nelson, M. A., \& Geist, M. R. (2006). Misconceptions about rate processes: Preliminary evidence for the importance of emergent conceptual schemas in thermal and transport sciences. In The 113th Annual ASEE Conference and Exposition Conference Proceedings. Chicago, I.L..

Mitchell, J., \& Martin, J. (2007). Personal communication (A 2004 question draft version of the heat transfer concept inventory, the University of Wisconsin).

Noack, A., Antimirova, T., \& Milner-Bolotin, M. (2009). Student diversity and the persistence of gender effects on conceptual physics learning. Canadian Journal of Physics, 87(12), 1269-1274. doi: 10.1139/P09-108

Nottis, K. E. K., Prince, M., \& Vigeant, M. (2008). Addressing misconceptions about heat transfer in undergraduate chemical engineering instruction. In The Northeastern Educational Research Association Conference. Rocky Hill, C.T..

Nottis, K., Prince, M., \& Vigeant, M. (2009). Development of an instrument to assess crucial concepts about heat transfer in undergraduate chemical engineering instruction. In The Seventh Annual Hawaii International Conference on Education. Honolulu, H.I..

Nottis, K. E. K., Prince, M., \& Vigeant, M. (2010a). Building an understanding of heat transfer concepts in undergraduate chemical engineering courses. US-China Education Review, 7(2), 1-8.

Nottis, K., Prince, M., \& Vigeant, M. (2010b, January). The effect of engineering major and gender on undergraduate engineering students' understanding of heat, temperature, and energy concepts. In The Eighth Annual Hawaii International Conference on Education. Honolulu, H.I..

Omar, N., Zulkifli, R., \& Hassan, R. (2009). Development of a virtual laboratory for radiation heat transfer. European Journal of Scientific Research, 32(4), 562-571.

Pascarella, E. T., Whitt, E. J., Edison, M. I., Nora, A., Hagedorn, L. S., Yeager, P. M., \& Terenzini, P. T. (1997). Women's perceptions of a "chilly climate" and their cognitive outcomes during the first year of college. Journal of College Student Development, 38(2), 109-124.

Peşman, H., \& Eryilmaz, A. (2010). Development of a three-tier test to assess misconceptions about simple electric circuits. The Journal of Educational Research, 103 (3), 208-222.

Petcovic, H. L., \& Ruhf, R. J. (2008). Geoscience conceptual knowledge of preservice elementary teachers: Results from the geoscience concept inventory. Journal of Geoscience Education, 56(3), 251-260.

Planinic, M., Boone, W. J., Krsnik, R., \& Beifuss, M. L. (2006). Exploring alternative conceptions from Newtonian dynamics and simple DC circuits: Links between item difficulty and item confidence. Journal of Research in Science Teaching, 43(2), $150-171$. 
Prince, M. (2009). Personal communication. Pennsylvania: Bucknell University.

Prince, M., \& Vigeant, M. (2006). Using inquiry-based activities to promote understanding of critical engineering concepts. In The ASEE National Conference. Chicago, I.L..

Prince, M., Vigeant, M., \& Nottis, K. (2009a). A preliminary study on the effectiveness of inquiry-based activities for addressing misconceptions of undergraduate engineering students. Education for Chemical Engineers, 4(2), 29-41.

Prince, M., Vigeant, M. \& Nottis, K. (2009b). Development of concept inventory in heat transfer. In The ASEE National Meeting. Austin, T.X.

Rosser, S. V. (2003). Attracting and retaining women in science and engineering. Academe, 89(4), 24-28.

Self, B. P., Miller, R. L., Kean, A., Moore, T. J., Ogletree, T., \& Schreiber, F. (2008, October). Important student misconceptions in mechanics and thermal science: Identification using model-eliciting activities. In The ASEE/IEEE Frontiers in Education Conference.. New York, N.Y.: Saratoga Springs.

Shallcross, D. C. (2010). A concept inventory for material and energy balances. Education for Chemical Engineers, 5, e1-e12.

Shuell, T. J. (2003). Toward an integrated theory of learning. In The Annual Meeting of the Northeastern Educational Research Association. Ellenville, N.Y.

Smith, E. L. (1991). A conceptual change model of learning science. In S. M. Glynn, R. H. Yeany, \& B. K. Britton (Eds.), The psychology of learning science (pp. 43-63). Hillsdale, N.J.: Lawrence Erlbaum.

Smith, J. P., diSessa, A. A., \& Roschelle, J. (1993). Misconceptions reconceived: A constructivist analysis of knowledge in transition. Journal of the Learning Sciences, 3(2), 115-163.

Streveler, R. T., Litzinger, T., Miller, R., \& Steif, P. (2008). Learning conceptual knowledge in the engineering sciences: Overview and future research directions. Journal of Engineering Education, 97(3), 279-94.

Streveler, R. T, Olds, B., Miller, R., \& Nelson, M. (2003). Using a Delphi study to identify the most difficult concepts for students to master in thermal and transport science. Proceedings of the 2003 American Society for Engineering Education Annual Conference \& Exposition. Nashville, T.N..

Suping, S. (2003). Conceptual change among students in science. ERIC Digest, ED482723.

Thomaz, M. F., Malaquias, I. M., Valente, M. C., \& Antunes, M. J. (1995). An attempt to overcome alternative conceptions related to heat and temperature. Physics Education, 30(1), 19-26.

Thorton, R. K., \& Sokoloff, D. R. (1998). Assessing student learning of Newton's Laws: The force and motion evaluation and the evaluation of active learning laboratory and lecture curricula. American Journal of Physics, 66(4), 338-351.

Whitt, E. J., Edison, M. I., Pascarella, E. T., Nora, A., \& Terenzini, P. T. (1999). Women's perceptions of a "chilly climate" and cognitive outcomes in college: Additional evidence. Journal of College Student Development, 40(2), 163-177.

Williams, M. M., \& George-Jackson, C. E. (2014). Using and doing science: Gender, self-efficacy, and science identity of undergraduate students in STEM. Journal of Women and Minorities in Science and Engineering, 20(2), 99-126.

Wyer, M. (2003). Intending to stay: Images of scientists, attitudes toward women, and gender as influences on persistence among science and engineering majors. Journal of Women and Minorities in Science and Engineering, 9, 1-16.

Wuttiprom, S., Sharma, M. D., Johnston, I. D., Chiaree, R., \& Soankwan, C. (2009). Development and use of a conceptual survey in introductory quantum physics. International Journal of Science Education, 31(5), 631-654.

\section{Appendix I}

Example of a question linked to experiential knowledge:

\section{Question 16}

Two thin, identical pizzas initially at room temperature are placed in separate pizza ovens, one for five minutes at $700{ }^{\circ} \mathrm{F}$ and the other for 10 minutes at $350^{\circ} \mathrm{F}$. If both pizzas are cooked to the precisely the same degree of doneness when they are removed, to which pizza was more energy added?

a. Not enough information provided.

b. The pizza cooked in the $700{ }^{\circ} \mathrm{F}$ oven for five minutes had more energy transferred to it.

c. The pizza cooked in the $350{ }^{\circ} \mathrm{F}$ oven for 10 minutes had more energy transferred to it.

d. Both pizzas had the same amount of energy transferred to them. 


\section{Appendix II}

Examples of questions incorporating multiple concepts and needing course content knowledge:

An engineering student has two beakers containing mixtures of dye in water. The first beaker has a $1 \%$ dye solution (one gram of dye in 100 grams of water) and the second beaker has an equal volume of a $2 \%$ dye solution (two grams of dye in 100 grams of water).

The student places two identical sponges in the $1 \%$ dye solution and one sponge in the $2 \%$ dye solution.

Question 22: Which of these combinations will absorb more dye?

a. The two sponges in the $1 \%$ solution will absorb more dye.

b. The one sponge in the $2 \%$ solution will absorb more dye.

c. Both systems will absorb the same amount of dye.

\section{Question 23: Which of these combinations will initially absorb dye at a faster rate?}

a. Two sponges in the $1 \%$ solution will absorb dye at a faster rate.

b. One sponge in the $2 \%$ solution will absorb dye at a faster rate.

c. Both systems will absorb dye from solution at the same rate. 